\title{
Don Ricardo Palma y la Masonería - Parte II
}

Por Ismael Pinto Vargas 
Abogado, periodista, doctor en Historia y Literatura en la Universidad Nacional Mayor de San Marcos. Trabajó en los diarios Última Hora y Correo, y en la revista Caretas. Editor de la sección cultural de Expreso. Miembro de Número de la Academia Peruana de la Lengua. 
En mi primera intervención ${ }^{1}$ de la biografía palmiana y/o palmista, referida a la participación activa y pública de don Ricardo Palma en los predios de la masonería peruana, decíamos que este transcurrir vital del Tradicionista, constituía una suerte de agujero negro. Un espacio en el que la información era notoriamente escasa. Y, en muchos casos, la existente se refería a algún tema puntual, o, muy de pasada, a nuestro elusivo masón. Y, en algún otro caso, si bien el personaje despertaba el interés del lector o del investigador, de pronto se perdía en medio de una información que, sin mayor esfuerzo, y brillantemente, se podía hallar en los trabajos de Edith o Angélica Palma, bien en Riva Agüero, Porras, Luis Alberto Sánchez, Jorge Guillermo Leguía, Oswaldo Holguín, José Miguel Oviedo, o en el punzante Julio Díaz Falconí, por mencionar solo alguno de sus más conspicuos estudiosos, amén de la larga pléyade de estupendos trabajos que sobre el Tradicionista y su obra viene incentivando y publicando, sin prisa pero sin pausa, la Universidad Ricardo Palma, y el Instituto Ricardo Palma, que ahora nos convoca.

Lo cierto y comprobado es que "un día miércoles 4 de julio de 1855, Ricardo Palma ingresa a la Masonería Peruana, a la edad de 22 años. Se inicia en la señera y tradicional logia del Callao 'Concordia Universal' registrada con el N 2 en el Gran Oriente

1 CF. Aula Palma XII / Instituto Ricardo Palma / Rectorado. Lima 2013, págs.207 a 228 
Peruano. Una logia fundada el 20 de setiembre de 1849"2. Su antecedente lo podemos encontrar, como lo señala el ingeniero Carlos López Albújar, maestro masón Grado 33, “en el grupo numeroso de hermanos que venían trabajando desde las luchas patrióticas por la independencia, en las prácticas del Arte Real agrupados bajo el título de 'Unión con la Marina Peruana. El grupo que conformaba esta logia temprana, solicitó y obtuvo su Carta Constitutiva con el No 2, del Gran Oriente Peruano, presidido por aquellos años por el Gran Mariscal Don Miguel de San Román, el año de 185 l”. Pero por ese entonces no solo nuestros cerriles padres de la patria andaban conspirando y de revolución en revolución. Vale decir, que también algunos cambios importantes se sucedieron dentro de la masonería peruana, obviamente sin tiros ni cierra puertas. Es así que aparece el Gran Oriente Nacional Peruano, dentro del cual, empieza a trabajar "Unión con la Marina Peruana", como "Concordia Universal No $14 " 3$.

Pero no nos alejemos de don Ricardo y de su iniciación masónica. Quien recibe a Palma para su ingreso oficial en este fascinante y siempre arcano mundo, y le da el toque y la palabra clave para ser reconocido como aprendiz masón, es "el Venerable Maestro Manuel Cipriano Dulanto". Estos últimos datos están sustentados en documentos, y quien los entrega antes de perderse afanoso en el universo profano de don Ricardo, es el doctor Alfonso Hart Bedoya -también masónen su miscelánico libro, Ricardo Palma / El Egregio Tradicionista e Ilustre Masón Peruano ${ }^{4}$.

2 Harth Bedoya, Alfonso. Ricardo Palma / El Egregio Tradicionista /e/ Ilustre Masón. Editorial "San Marcos", Lima 1992, págs. 31 y sgts.

3 Carlos López Albújar. Masones y Masonería en el Perú, Lima 1961, pág. 343.

4 Editorial “San Marcos”, Av. Garcilaso de la Vega 911, Lima, 1992. 
Ahora bien, no debemos perder de vista que el acercamiento de Palma a la masonería chalaca lo podemos encontrar, de alguna manera, en su nombramiento como contador del vapor "Loa". Trabajo que le exigía estar en cercano contacto con personas y personajes del mundo del Callao y La Punta. Y, trabajo, o mejor diríamos, canonjía y admirable escape que le proporcionó a Palma "el doctor Miguel del Carpio, magistrado, estadista y literato (que) era el mecenas de la bohemia... - y como recuerda don Ricardo- del Carpio se complacía en que asistiéramos a su tertulia nocturna, en la que nos agasajaba con exquisito moka, delicioso chocolate de Apolobamba y riquísimos habanos. Corpancho, Mansilla, García, Camacho Arguedas, Fernández, Pastor, Sánchez Silva y yo, éramos los más asiduos"5. Vale decir, con palabras de hoy en día, que el susodicho magistrado mistiano, algo ya mayorcito, tenía una marcada predilección por departir con los jóvenes, sobre todo si eran literatos.

Lo cierto es que, como el memorioso Palma lo evoca sin llegar al fondo del asunto, el susodicho trabajo, conseguido por el doctor del Carpio, no era otra cosa que una vergonzosa huida: poner el amplio océano de por medio, entre una novia que demandaba casorio y una frustrada suegra que exigía la reparación del daño causado a su inocente hija. Pero el empeñoso enamorado no tenía dentro de sus planes perder su cerril soltería. Raúl Porras, en su delicioso texto titulado Palma Romántico, con cierta sorna califica al Palma de esta etapa como un aprovechado "aprendiz de Tenorio".

Pero, volvamos a lo nuestro y dejemos de lado la picaresca vida sentimental del joven Palma. Si bien ha quedado meridianamente establecido que ingresó y perteneció a la "Logia Concordia Universal $N^{\circ} 14$ " del Valle del Callao, es un tanto

5 “La bohemia de mi tiempo". En Ricardo Palma, Tradiciones Peruanas Completas. Aguilar, Madrid, 1961, pág. 1298. 
desconcertante, por decir lo menos, no encontrar en boletines ni en la Revista Masónica, órgano oficial de la Orden, material historiable sobre el paso, la permanencia y el quehacer del tradicionista en los diversos predios de la hermandad secreta de la escuadra y el compás.

Y, en esta suerte de tejer una suerte de tela de araña alrededor de Palma y sus sumersas actividades masónicas, uniendo puntos que pueden conformar un perfil más nítido, podemos agregar un dato importante. Esto por declaración del propio Palma, quien recordaba que en cada arribo al Callao, después de sus interminables viajes, él y don Miguel Grau Seminario, iban juntos a trabajar con su venerable Maestro en la 'Logia Luz Austral' que laboraba en el Callao en la antañona y sobreviviente casona que se halla, hoy por hoy, frente al local del Teatro de nuestro primer puerto. Y aquí, a mayor abundamiento, y de acuerdo con la versión masónica, también de Palma, de la pertenencia de Grau a la hermandad, don Miguel "habría sido invitado a pertenecer a la orden masónica en la 'Logia Unión Indisoluble' en el Valle de Piura; sin embargo lo haría más tarde en Paita". Y uniendo cabos sueltos y yendo un poco más lejos, tenemos que el padre de Grau, esto es, el caballero don Manuel Grau habría sentado sus reales en Lima el año de 1848, integrándose de inmediato a la Sociedad Fraternidad, Igualdad y Unión, "que reunía en su seno a quienes habían sido calificados como participantes en las Campañas de la Independencia, que años más tarde se convertiría en la Benemérita Sociedad de Fundadores de la Independencia y Defensores Calificados de la Patria"'.

6 María Inés Valdivia. El Liberalismo Social en el Perú. Masones, Bomberos, Librepensadores y Anarquistas Durante el Siglo XIX. ANR Asamblea Nacional de Reactores, Lima, junio 2010, págs. 58, 59, 60, 61. 
Volviendo al año de 1857, tenemos que el joven Palma continuó trabajando en su madre 'Logia Concordia Universal'. Harth Bedoya en su ya citado miscelánico trabajo nos dice que "es después de aquel año -sin poder establecerse fecha - que figura en el Libro del Taller su pase a la 'Logia Virtud y Unión', cuando ostentaba ya el grado de Maestro Masón”. Lo que implica que Palma había trabajado en su madre Logia presentando trabajos y otros que, de acuerdo a reglamentos internos de cada logia y taller, le sirvieron para pasar de aprendiz a hermano y de ahí al tercer grado: el de maestro. No obstante no hay huellas de esos adelantos.

En el mismo año de 1857 aparece el nombre de don Ricardo entre los masones que desconocieron el Gran Oriente al que pertenecían las distintas logias peruanas, conformando un organismo autónomo bajo el nombre de Gran Logia Nacional del Perú. Ya por aquellos años don Ricardo no es un masón cualquiera. Es un masón con un respetable prestigio literario, como también un burlón y aguerrido periodista que había tenido más de un encontronazo o una encendida polémica. Personaje que, en buena cuenta, daba prestigio y lucimiento a cualquier institución a la que perteneciera. Un nombre que, ahora consideramos, debía estar exento de todo olvido.

No obstante, en el folleto conmemorativo para la celebración de los 124 años de vida masónica institucional, de la mencionada 'Logia Concordia Universal', publicado el año de $1976^{7}$, en el acápite Nuestra palabra, se anota: "Quienes conocemos la historia de nuestra Respetable y Benemérita Logia, sabemos que el Taller ha sabido resistir las más crudas inclemencias y las más fuertes tempestades. Pero este hecho ha sido consecuencia

7 RES:. Y BEN:. LOG:. SIMB:. / "Concordia Universal» $N^{\circ}$ 14/ Fundada el 20 de Setiembre de 1849 / Vall:. Del Callao / Ten:. Solemne de Aniversario / Vall:. Del Callao, 19 de Setiembre de 1976 E: V:. 
de la voluntad inquebrantable de nuestros hermanos mayores que hoy moran en el Oriente Eterno". Y, después de dar la plancha, vale decir en palabras de un profano, a la lista en la que aparecen los nombres de la directiva de aquel año, se da un muy pequeño espacio para incluir la nómina de sus fundadores y de los más relevantes personajes que habían pertenecido a la susodicha logia.

Y si allí aparece y desaparece con igual rapidez el nombre de don Manuel Cipriano Dulanto, el hermano masón que recibió e inició al joven Palma en esa venerable y antigua logia chalaca, no obstante, allí brillan ostensiblemente, por su ausencia, otros notorios personajes de nuestra historia. Tal el General Juan Antonio Pezet, que fue Gran Maestre de esa Logia, siendo también y al mismo tiempo Presidente de la República, como el nombre del doctor Alejandro Deustua, eminente catedrático de filosofía de la Universidad Nacional Mayor de San Marcos. De Pezet ya lo sabíamos, nuestra sorpresa ha sido encontrar al doctor y filósofo Alejandro Deustua en estos elusivos menesteres. Y, sin abundar más, la ausencia de Palma, que siendo uno de los miembros más importantes dentro de la historia de la masonería peruana en particular, como de la historia de la literatura peruana en general, y si lo vemos fríamente, el personaje histórico más importante que haya pasado por 'Concordia Universal', ni siquiera es mencionado, en esas escuetas, apretadas y olvidadizas páginas.

Debemos rescatar que, si bien años después, también profesó en esa logia un personaje que está dentro de la historia de la infamia histórico-política de nuestro ya fenecido y un tanto lejano siglo XX: el mayor E.P. más conocido como "el negro" José Vásquez Benavides -masón Grado 32-, ${ }^{8}$ que tundiera malamente a José Carlos Mariátegui por algún artículo que no

8 Carlos López Albújar. Masones y Masonería en el Perú, Lima 1961, pág. 343. 
les gustó a los valientes soldados de aquellos años. Pero esa es otra historia, que no deja por cierto bien parados a los masones de Concordia Universal, la logia de don Ricardo.

En otras palabras, y volviendo al caso específico de Palma, que es el que nos interesa, su madre logia, en el año de 1976, cometió un grosero olvido. Se obvió a Palma y a otros personajes que prestigiaban y engalanaban a esa Logia, para dar espacio a la vanidad: fotografías de la directiva de ese momento, resaltando trabajos y nombres que, me atrevería a decir, hoy, ni dentro de la misma orden se mencionan. Tampoco se recuerda el nombre de Henry Meiggs que, hasta donde tengo entendido, fue quien regaló la gran casa, frente al teatro del Callao, para que allí trabajasen, como hoy día trabajan, las distintas y activas logias masónicas que operaban y operan en el denominado ,masónicamente, Valle del Callao. Como podemos ver, hay muchas historias dentro de esta historia palmiana.

Por otro lado, debemos admitir que en las distintas entregas de la Revista Masónica / Órgano Oficial de la Masonería del Perú, es un tanto difícil seguir las huellas de don Ricardo en los avatares y recovecos de su activa vida, tanto en su logia "Estrella Boreal No 74", como en "Concordia Universal", porque prácticamente casi son inexistentes. $\mathrm{O}$, encontrarnos de pronto con su nombre, mencionado muy de pasada, tal en la Revista Masónica ${ }^{9}$, correspondiente al año 1889, en la que se da a conocer los miembros activos de "Estrella Boreal No 74". Allí, se anota: "Relación de los Miembros de la Sob:. Cap:. / Estrella Boreal No 74 / Por Orden de Antigüedad..."10 Entre un maremágnum de nombres, Palma figura con el numero

9 La Revista Masónica del Perú / Órgano de la Masonería Simbólica del Perú. / Director - Redactor H.: Eduardo Levergne. Año VIII, No 95. Lima, Setiembre 30 de 1889.

10 Ibídem. 
cuarenta, entre los más de quinientos miembros activos de esa Logia. En contrario, sí hay casos, por ejemplo, de otros personajes que, como es el de Gerardo Cabello, el hermano de Mercedes Cabello de Carbonera, que pertenecía a la muy activa "Logia Honor y Progreso No 5", en que, sin mayor esfuerzo se puede reconstruir, fácilmente, a través de los cargos ejercidos y las intervenciones y publicaciones efectuadas, su paso y sus logros obtenidos en los cerrados predios de la masonería en general, y de su logia, la mencionada "Honor y Progreso $N^{\circ} 5$ ", en particular. Lo reiteramos, lo que no sucede con Palma.

No obstante lo anotado, sí tenemos una notoria y pública intervención de don Ricardo, que involucra sus actividades tanto profanas cuanto masónicas. Es el caso concreto en que aparece como uno de los más decididos y entusiastas promotores liberales para que se expulse a la Compañía de Jesús de tierras peruanas. Y esta vez no era Carlos III ni su ministro ilustrado, el Conde de Aranda, que en 1767 extrañaron a la Compañía de todo el virreinato peruano. Esta vez, se habían comprado el pleito los liberales y los masones peruanos ${ }^{11}$. Y como antecedente intelectual y anti jesuítico estaba la publicación de una Historia Compendiada del Perú. Sobre el tema, podemos acotar una aseveración de Julio Días Falconí, palmista convicto, confeso y desconfiado, que nos asegura un tanto indignado que "Palma nunca dijo que era masón. En sus confabulaciones políticas hay hondas raíces masónicas. Se declaraba liberal, mas no masón, a pesar de que actuaba a la sombra de masones archiconocidos, como José Gálvez que luchaban contra el gobierno autoritario y corrupto de Ramón Castilla"12.

11 López Albújar, Carlos, ob. cit.

12 Díaz Falconí, Julio. Los Padrinazgos de Ricardo Palma. Pequeña Biblioteca de Literatura Regional Vol. 8. Papel de Viento Editores, Trujillo, Perú, 2007, pág. 45 y sgts. 
Al parecer, la percepción de Díaz Falconí no era muy gratuita. Incluso, a través del tiempo, la podemos ver reflejada, de alguna manera muy sutil, en los dos trabajos de López Albújar. Esto en lo que se refiera a las dos ediciones de Masones y Masonería en el Perú, las de 1958 y la de 1961. Y aquí, debo confesar que no sé si la acotación de Díaz Falconí me ha predispuesto a encontrar lo que él menciona, o si bien por un prurito de exagerada sutileza yo lo estoy acotando a la mala. Lo cierto es que, volviendo a las dos ediciones de la obra de don Carlos López Albújar, tenemos que en la primera aparece un medallón con el rostro de Palma y solamente una leyenda con su nombre. En la segunda edición -corregida y sobre todo aumentada- tres años después, el medallón de don Ricardo lleva la siguiente inscripción: "I de E.H. Ricardo Palma, Gr. $8^{\circ}{ }^{13}$.

Pero, si queremos seguir indagando dentro del derrotero insinuado por Díaz Falconí, velis nolis, nos topamos con la singular manera que tiene López Albújar para referirse a Palma, esto dentro del conflicto que creó el jesuita Ricardo Cappa, cuando publicó el ya mencionado, cuestionado y polémico libro Historia Compendiada del Perú. Así, López Albújar, obviando calificar a Palma como hermano, o, simplemente, como masón se refiere a él como el "ilustre autor de las incomparables tradiciones Peruanas, al reconocer el grave ataque a la verdad histórica contenida en la dicha obra del padre Cappa, la impugnó..." Más adelante nos dice que "A la impugnación de don Ricardo Palma sigue la voz de protesta levantada en la Cámara de Senadores..."14, se organizan mítines en que mascarón de proa de los masones fueron los estudiantes de Lima y la ciudadanía, el primero casi fue un fracaso, el segundo sí fue tumultuoso. Y finalmente lo que liberales -léase bien- y masones lograron: que la Convención Nacional

13 López Albújar, obs. cit. págs. 54 y 229.

14 Ibídem, págs. 229, 230 y sgts. 
del Perú decretara en artículo único que "No es permitido el establecimiento de la Compañía de Jesús en territorio de la República”. Por otro lado la contribución palmiana efectiva fue el texto que publicó bajo el título Refutación a un texto de historia, que, con coloquial expresión robada a sus tradiciones, Palma hizo cera y pabilo del trabajo histórico del padre Cappa S.J. Entre lo severo y crítico don Ricardo no puede dejar de lado su ironía punzante y burlona; es así que registra aquel inolvidable párrafo que empieza: "Mi colombroño -es decir mi tocayo- el padre Cappa es un comodín, una especie de agnus obligado a cargar con los pecados de la Compañía, en el Perú. Cuando recientemente, la discreta e ilustrada autoridad eclesiástica prohibió una mascarada carnavalesca, en obsequio de San Luis Gonzaga, quedándose pontifiquito, cardenalitos, zuavitos, frailucos y angelitos con los crespos hechos, el superior de los jesuitas se lavó las manos colgando el mochuelo al fantástico batallador ex marino Ricardo Cappa. O se han desvirtuado y descendió mucho la Compañía, para que en ella ande todo manga por hombro, y haga y escriba cada miembro lo que en antojo le venga, o hay que considerar las disculpas como nueva e insolente burla al decoro de la autoridad y el buen sentido del país"... Para agregar ya indignado "Valiente historia la que el padrecito pretende enseñar a nuestros hijos"15. Quien quiera ahondar y especular sobre el tema debe consultar el raro folleto del doctor Christian Dam, solicitado dentista limeño y conocido masón comecuras, titulado Breve Reseña sobre la historia de los jesuitas ${ }^{16}$.

Y hasta aquí llegamos en esto de tejer lazos y rebuscar relaciones de continuidad. Como vemos, este intento de lo que podríamos

15 Ricardo Palma. "Refutación a un texto de Historia". En: Mis últimas Tradiciones Peruanas / Cachivacherías. Casa Editorial Maucci. Barcelona, España, 1900, págs. 501 a 522.

16 Imp. Liberal Unión (Boza) 1907. 
calificar de la vida secreta de Palma, complejo entramado de profanos, liberales y masones, entre los nombres de cuatro presidentes de la República: La Mar, San Román y Pezet, connotados masones, aunque San Román abjuró en artículo mortis, con cura confesor y acto de contrición, y don Miguel Iglesias, el denostado Presidente que firmó la paz con Chile, y allí entre muchos nombres los de Grau, y Deustua, a los que podríamos agregar, antes, los de Francisco Javier Mariátegui, Francisco Xavier de Luna Pizarro -sí, el fraile liberal-, como don José Gálvez Barrenechea en el pasado siglo XX, y su homónimo del XIX, que complotó con Palma para matar a Castilla, sacrificado en el combate del 2 de mayo. Y tantos otros que harían, de esta charla algo interminable y altamente sospechosa de propaganda subliminal, incitando a algún miembro de este selecto auditorio de querer ingresar a la elusiva orden que profesó obedientemente don Ricardo.

Ahora, vamos a permitirnos ubicar a Don Ricardo ya un tanto mayorcito y con el prestigio de su fama bien ganada y su mala lengua a cuestas. Y es, obviamente un espacio que también tiene que ver con la masonería. El del epistológrafo comedido en unos casos, chismoso panfletario y con toda la mala leche del mundo; otros, como el patriota indignado y dolido por la derrota y la humillación sufrida por el Perú, en una guerra prefabricada y expansionista.

Como es de todos conocidos a la edición del Epistolario Vol. I y II, publicado por las palmeritas Augusta y Renée Palma, con un magistral Prólogo de Raúl Porras Barrenechea (Editorial Cultura Antártica S.A. Lima 1949). Por otro lado, el denominado Epistolario General (Universidad Ricardo Palma / Ed. Universitaria, Lima, 2005) que ha refundido en sus páginas la edición de 1949, y los que después de esa edición han aparecido, debido al trabajo de recopilación de Miguel Ángel Rodríguez Rea. 
Y aquí podemos mencionar dos epistolarios de don Ricardo. El primero: ${ }^{17}$ Cartas Inéditas de Don Ricardo Palma. Introducción y Notas de Rubén Vargas Ugarte S. J., es decir, de la Compañía de Jesús. Y el otro epistolario: Ricardo Palma / Crónicas de la Guerra con Chile (1881 - 1883) compilación de C. Norman Guice, con la colaboración de Oswaldo Holguín Callo y un prólogo de Héctor López Martínez ${ }^{18}$. Que de alguna manera están ligados al transcurrir masónico de Palma.

El primero, misivas del cumplido y, a veces chismoso, informante de Piérola. Penosa etapa de nuestra maltrecha historia cuando don Nicolás fungía de Presidente y andaba a salto de mata de un país ocupado y depredado por la soldadesca chilena. Y, aquí, debo confesar hidalgamente que hasta la fecha no encuentro una explicación lógica de la para mí rara amistad que unía realmente a estos dos personajes, fuera de su animadversión al civilismo. Piérola era un hombre de la iglesia a rajatabla y Palma, insolente masón anticlerical y comecuras. Es más, don Ricardo se permite recomendar a don Nicolás a un conspicuo y conocido masón. Así Palma escribe: "El dador de esta carta es mi amigo el Dr. Gerardo Cabello, leal y constante partidario de U. Se lo recomiendo muy mucho. Es joven ilustrado e inteligente. El explicará a U. las dificultades con que brego para abandonar Lima e irme a su lado"19. Gerardo Cabello, hermano de Mercedes Cabello de Carbonera, era un notable miembro de la Logia "Honor y Progreso $N^{0}$ 5", cuyas actividades en la vida diaria limeña habían trascendido las paredes de su taller

17 Ricardo Palma / Cartas Inéditas. Introducción y Notas de Rubén Vargas Ugarte S. J. Editor: Carlos Milla Batres. Lima, Perú, 1964.

18 Ricardo Palma / Crónicas de la Guerra con Chile (1881 - 1883.) Compilación, introducción y notas de C. Norman Guice / con la colaboración de Oswaldo Holguín Callo / Prólogo de Héctor López Martínez. Mosca Azul Editores, Lima, 1984.

19 Ricardo Pal,a Cartas Inéditas. Introducción y Notas de Rubén Vargas S. J. Editor: Carlos Milla Batres, Lima, Perú, 1964, pág. 38. 
que trabajaba en el denominado Callejón de San Francisco, a escasos metros de la casa de don Nicolás. Y actividades que don Nicolás no podía ignorar, como tampoco podía ignorar los nombres, y hasta conocer a los liberales y masones, o al revés, que allí se reunían. Como no hay misivas de respuesta a la correspondencia de Palma, no sabremos nunca la respuesta de don Nicolás a este singular pedido de su epistológrafo.

Yel otro epistolario, que reúne la correspondencia de Palma como un puntual cronista con sus textos especialmente escritos para el hebdomadario El Canal, publicado en Panamá, por Federico Larrañaga. Un diario peruano que, fuera de nuestro territorio, defendía ante los ojos de una América inexplicablemente silenciosa, los intereses del maltratado y ocupado Perú. [Debo anotar aquí que ambos han sido incluidos en tres volúmenes publicados por la Universidad Ricardo Palma].

No nos vamos a referir al contenido de las cartas, sí a algo que está profundamente ligado a la pertenencia de Palma a la Orden masónica. Y esto se da, de alguna manera, en el seudónimo usado por el diligente corresponsal. En este caso el pseudónimo, se constituye en una suerte de cordón umbilical entre esos dos testimonios contemporáneos. Uno de carácter particular y el otro de índole público y sobre el mismo tema, aunque con diversos tonos. Me estoy refiriendo al seudónimo: Hiram, con el cual está signada toda la correspondencia del Palma periodista y panfletario, para el mencionado semanario El Canal. Y pseudónimo que también es, intermitentemente, usado en las amicales y chismosas cartas enviadas a su amigo Piérola.

Si bien encontramos un texto temprano, en 1894, con la autoría de Hiram interrogándose sobre ¿Cuál será el porvenir / de la Raza Humana?20, lo descartamos ya que está muy lejos

20 La Revista Masónica / Del Perú, ob. cit. № 154, agosto 31, 1894, pág, 117 y 118. 
de la prosa y el empaque y el regusto por la palabra de don Ricardo. Ahora bien, cuál es el significado y el contenido que esconde este significativo pseudónimo dentro de los predios de la masonería no solo peruana sino universal. Como anota un serio investigador de los arcanos de la Orden masónica, esta no se entendería sin la leyenda iniciática del Maestro Hiram, "y de todo cuanto ella representa en el itinerario espiritual del masón, y en torno de quien se estructura toda la ceremonia de iniciación del tercer grado". Muerte y resurrección por las que un miembro de la Orden va pasando, en el transcurso del largo viaje de su perfeccionamiento espiritual, que no es otra cosa que el acceso a cada nuevo grado, que constituye una ordenada vida masónica. Y como hemos podido ver por lo anotado, Palma fue un masón que se sometió y cumplió con los trabajos requeridos para alcanzar dichos grados ${ }^{21}$.

El francés Frederic Lenoir ${ }^{22}$ que se ha adentrado en el mundo masónico tratando de develar sus secretos registra que "ideal de los constructores de las catedrales de la edad media, el Templo de Salomón se convirtió, así, de un modelo simbólico en el de los masones modernos. Aquí entra en escena el personaje bíblico Hiram. El albañil más consumado de la tierra, que es vinculado al grado de maestro que tras los de aprendiz y de masón corona la iniciación masónica". La tradición señala que Hiram es el albañil que construyó el Templo de Salomón, y si bien aparecen tres personajes nominados Hiram, el que está ligado a la Orden "es Hiram Abi artesano del bronce, hijo de un tirio y de una viuda de la tribu israelita de Neftalí". De allí también que a los masones se le designe como "hijos de la Viuda".

21 Francisco Ariza. La Tradición Masónica / Historia, Simbolismo, Documentos Fundadores. Ediciones Obelisco. Barcelona, España, 2008, pág. 69 y sgts.

22 Frederic Lenoir / Marie-France Etchegoin. La Saga de los Massones. Ediciones B. Barcelona, España, 2009. Págs. 135 y sgts. 
Ahora bien, ahondemos, antes de terminar, algo más sobre Hiram. Este personaje como maestro de obras del templo de Salomón es el que "organiza a los obreros en tres grados: aprendices, compañeros y maestros, cada uno de ellos con su propia consigna, que permite en especial percibir el salario en relación con su calificación. Pues bien, cierto día tres compañeros tratan de arrancar a Hiram la consigna correspondiente al grado de maestro albañil y como este se niega, muere golpeado, durante la noche por cada uno de ellos con las herramientas de su trabajo: martillo, cincel y compás". De allí el celosamente guardado secreto de los signos y lemas o consignas y palabras para el reconocimiento de quienes pertenecen a la Orden y a los diversos grados que en ella se ha alcanzado.

Finalmente, este relato mítico convierte a Hiram en la encarnación del "albañil consumado". Y pone de relieve su integridad moral y su valor, puesto que prefiere la muerte a revelar los secretos de los que es depositario. Sintomáticamente, este es el personaje bajo el que se refugia Palma, jugándose la vida en momentos en que Lima está ocupada por el ejército chileno, y la vida de los peruanos no valía nada cuando se hallaba el menor atisbo de resistencia. Por otro lado Hiram también es el emblema de la construcción del templo interior, erigido laboriosamente en el corazón de todo masón. Aquí nos hacemos un interrogante, ¿Palma consiguió levantar ese templo interior? Eso, ya nunca lo sabremos. El interrogante y la discusión, quedan en pie. Lo que sabemos es que don Ricardo llevó una vida paralela y secreta a la pública que todos conocemos. Y que tan solo apenas hemos vislumbrado. 